\title{
COTEJO DE MANUSCRITOS DO SÉCULO XIX
}

\author{
Elias Alves de Andrade*
}

Resumo: Este artigo tem por objetivo o estudo filológico de dois manuscritos do século XIX, o primeiro (Ms1), escrito em Mariana - MG, em 8 de fevereiro de 1812, e o segundo (Ms2), sem indicação de data e local, pertencentes ao Arquivo Público do Estado de São Paulo, ambos cópias, sendo o Ms2 cópia do Ms1. Para tanto, foram feitas as edições fac-similar e semidiplomática, buscando-se, através do cotejo dos dois documentos, analisar as diferenças e semelhanças detectadas entre eles e efetuar os comentários paleográficos.

Palavras-chave: Crítica textual; filologia; manuscrito; edição; paleografia.

\section{Introdução}

Seguindo-se princípios da filologia e da crítica textual, este artigo tem por objetivo fazer o cotejo entre dois manuscritos do século XIX: o Ms1, datado de 08.02.1812, Mariana-MG, e o Ms2, sem indicação de data e local, pertencentes ao Arquivo Público do Estado de São Paulo, acondicionados na lata 88, pasta 2, ordem 0-334, identificada como: "S. Manuscritos, T. C. Minas Gerais, Mato Grosso, Goiás, Excursão do General Rodrigo Cesar de Menezes àquelas localidades, 1721-1822", visando à abordagem de aspectos

* Universidade Federal de Mato Grosso. 
paleográficos e das diferenças existentes entre ambos, fruto das intervenções do escriba, copista ou amanuense.

Tendo por suporte as edições fac-similar e semidiplomática, além de procurar mostrar os desafios que o editor enfrenta ao se deparar com a tarefa de editar textos, quando se dispõe de cópia (Ms1) da qual se origina outra cópia (Ms2) atestada, entretanto, por terceiro, espera-se contribuir para o estabelecimento dos textos, preparando-os para o trabalho do linguista.

Essa atividade está articulada com os projetos de pesquisa "Estudo do português em manuscritos produzidos em Mato Grosso a partir do século XVIII" - MeEL/IL/UFMT; e "História e variedade do português paulista às margens do Anhembi" e "Edição de textos literários e não literários em língua portuguesa" - FFLCH/USP.

\section{Paleografia}

\subsection{Histórico e definições ${ }^{1}$}

A paleografia, definida etimologicamente pelo grego palaios ("antigo") e graphien ("escrita"), é a "ciência que estuda a escrita antiga", ${ }^{2}$ atentando-se também para a dificuldade de leitura que essa escrita acarreta, "pelo fato de a escrita antiga apresentar caracteres diferentes dos da escrita atual."

Spaggiari e Perugi ${ }^{4}$ entendem que a paleografia, disciplina complementar à codicologia, "tem como fim o estudo dos caracteres gráficos antigos", nisto concordando com Acioli, ${ }^{5}$ que a define como

\footnotetext{
${ }^{1} \mathrm{O}$ tratamento teórico deste sub-item consta, no que se refere a conteúdo e forma, também em: ANDRADE. Aspectos paleográficos em manuscritos dos séculos XVIII e XIX, p. 149-172.

${ }^{2}$ DIAS; BIVAR. Paleografia para o período colonial, p. 11-38.

${ }^{3}$ ACIOLI. A escrita no Brasil Colônia, p. 5.

${ }^{4}$ SPAGGIARI; PERUGI. Fundamentos da crítica textual, p. 17.

${ }^{5}$ ACIOLI. A escrita no Brasil Colônia, p. 5.
} 
a ciência que lê e interpreta as formas gráficas antigas, determina o tempo e lugar em que foi redigido o manuscrito, anota os erros que possa conter o mesmo, com o fim de fornecer subsídios à História, à Filologia, ao Direito e a outras ciências que tenham a escrita como fonte de conhecimento.

Por sua vez, Blanco afirma que a paleografia é "a ciência que ensina a ler corretamente toda a classe de documentos manuscritos ou impressos, abordando também a origem e evolução da escrita.”

Cambraia, ${ }^{7}$ definindo também a paleografia, a exemplo dos autores citados, como o "estudo das escritas antigas", assegura que, modernamente, ela tem finalidade tanto teórica quanto pragmática: teórica, porque expressa a "preocupação em se entender como se constituíram sócio-historicamente os sistemas de escrita"; pragmática, porque visa à "capacitação de leitores modernos para avaliarem a autenticidade de um documento, com base na sua escrita", além de poderem interpretar de maneira adequada as escritas antigas. ${ }^{8}$

$\mathrm{Na}$ mesma direção, Spina9 afirma que a paleografia é "o estudo das antigas escritas e evolução dos tipos caligráficos em documentos", em material perecível (papiro, pergaminho e papel), posição corroborada por Azevedo Filho, ${ }^{10}$ que assegura estar a paleografia "voltada para o estudo gráfico de textos antigos [...]

\footnotetext{
${ }^{6}$ BLANCO. Estudos paleográficos, p. 13.

${ }^{7}$ CAMBRAIA. Introdução à crítica textual, p. 23.

${ }^{8}$ CAMBRAIA (Introdução à crítica textual, p. 23-24) afirma: "A paleografia constitui-se como ciência bastante relevante para a crítica textual, uma vez que auxilia na fixação da forma de um texto, para o que é necessário decodificar a escrita em que seus testemunhos são lavrados".

${ }^{9}$ SPINA. Introdução à edótica, p. 18.

${ }^{10}$ AZEVEDO FILHO. Iniciação à crítica textual, p. 19.
} 
escritos em material perecível, como o papiro, o pergaminho e o papel." 11

De acordo com Dias e Bivar, ${ }^{12}$ as origens dos estudos paleográficos remontam à Guerra dos Trinta Anos (1618-1648), entre protestantes e católicos, quando teriam sido constatados diversos casos de falsificação de documentos de posse ou propriedade sob litígio.

Segundo Cambraia, ${ }^{13}$ a paleografia, que "como campo de conhecimento sistematizado costuma ser situada no século XVII", foi estabelecida pelo jesuíta Daniel van Papenbroeck (1628-1714), o qual, por ter-se deparado, em viagem pela Europa, com muitos documentos falsos, escreveu a obra Propylaeum antiquarium circa veri ac falsi discrimen in vetustis membranis, na Antuérpia, em 1675, em que apresenta critérios para distinguir documentos falsos de verdadeiros. O monge beneditino Jean Mabillon (1632-1707), a propósito de críticas de Papenbroeck sobre documentos da Abadia de Saint-Denis, escreve a obra De re diplomatica libri IV, em Paris, em 1681, "em que avança ainda mais na investigação dos tipos de escrita". ${ }^{14}$ A paleografia consolida-se como ciência, entretanto, apenas com a obra Paleographia graeca sive de ortu et processu litterarum graecarum, escrita em Paris, em 1708, pelo beneditino Bernard de Montfaucon (1655-1741).

\footnotetext{
${ }^{11}$ SPINA (Introdução à edótica, p. 17-18) faz distinção entre:

a) Memória - objeto desprovido de inscrição: coluna, pirâmide, arco triunfal, árvore plantada, edificação;

c) Documento - objeto da paleografia, é o artefato feito em material mole, com inscrição: papiro, pergaminho e papel.

b) Monumento - objeto da epigrafia, é o artefato feito de material duro, com inscrição:

* Numária - estudo das moedas;

* Numismática - estudo das medalhas, atualmente também das moedas;

* Lapidária - estudo das inscrições; e

${ }^{12}$ DIAS; BIVAR. Paleografia para o período colonial, p. 14.

${ }^{13}$ CAMBRAIA. Introdução à crítica textual, p. 23.

${ }^{14}$ CAMBRAIA. Introdução à crítica textual, p. 23.
} 
Para Dias e Bivar, ${ }^{15}$ os estudos paleográficos no mundo ocidental podem ser divididos, desde sua origem, em três períodos de análise:

a) paleografia antiga ou greco-romana - do século $\mathrm{V}$ a.C. ao século VII d.C.;

b) paleografia medieval - do século VII ao século XV; e

c) paleografia moderna - do século XVI ao século XIX.

Para que se proceda a comentários de natureza paleográfica a propósito da edição de um texto, a exemplo do que se propõe fazer aqui a partir das edições fac-similar e semidiplomática de Ms1 e de Ms2, Cambraia ${ }^{16}$ indica deverem ser abordados os seguintes aspectos: ${ }^{17}$

a) classificação da escrita, localização e datação;

b) descrição sucinta de características da escrita, a saber: a morfologia das letras (sua forma), o seu traçado ou ductus (ordem de sucessão e sentido dos traços de uma letra), o ângulo (relação entre os traços verticais das letras e a pauta horizontal da escrita), o módulo (dimensão das letras em termos de pauta) e o peso (relação entre traços finos e grossos das letras);

c) descrição sucinta do sistema de sinais abreviativos empregado na referida escrita;

d) descrição dos outros elementos não-alfabéticos existentes e de seu valor geral: números, diacríticos, sinais de pontuação, separação vocabular intralinear e translinear, paragrafação, etc.;

\footnotetext{
${ }^{15}$ DIAS; BIVAR. Paleografia para o período colonial, p. 17-18.

${ }^{16}$ CAMBRAIA. Introdução à critica textual, p. 24.

${ }^{17}$ ACIOLI (A escrita no Brasil Colônia, p. 7-63) aborda, a propósito, também os seguintes aspectos: superfícies, tintas e instrumentos utilizados na escrita, sua origem, evolução e tipos, sinais braquigráficos (abreviaturas) e estigmológicos (pontuação e acentuação).
} 
e) descrição de pontos de dificuldade na leitura e as soluções adotadas.

\subsection{Comentários paleográficos de Ms1 e Ms2}

\subsubsection{Tipos de letras}

Os documentos Ms1 e Ms2 editados sob a forma fac-similar e semidiplomática a seguir são manuscritos produzidos por mãos hábeis, ou seja, os escribas, copistas ou amanuenses que produziram Ms1 (cópia, a partir do original, provavelmente) e Ms2, que é cópia de Ms1, neste caso elaborado a pedido de um terceiro, constituem-se de pessoas letradas, tendo, por ofício ou por formação, certamente sido submetidas a instrução formal.

Prova disso é que Ms1 e Ms2 registram escrita regular quanto ao traçado das letras, homogeneidade de seu tamanho, sem borrões ou rasuras, respeito à pauta, regularidade na inclinação da escrita à direita, uniformidade nas margens do fólio - esquerda e direita, recto (r), e verso (v) - ${ }^{18}$ dentre outras características.

A escrita usada em Ms1 e Ms $2^{19}$ foi a humanística ou italiana, com tipo de letras cursivas, caracterizadas por serem corridas, traçadas sem descanso da mão, apresentando muitas vezes nexos intravocabulares, além, noutras vezes, do não estabelecimento de fronteira entre palavras, especialmente em Ms2, o que pode levar a uma maior dificuldade de leitura em algumas situações, embora não seja este o caso dos documentos em análise. ${ }^{20}$

\footnotetext{
${ }^{18}$ Denomina-se recto (r) a face da frente e verso (v) a face de trás do fólio. ${ }^{19}$ Spina (Introdução à edótica, p. 35) afirma que "O Renascimento [...] relegou o estilo gótico pela sua profusão de artifícios, e voltou as suas simpatias para um tipo de letra mais simples e mais pura", reabilitando a antiga minúscula carolina, redundando na escrita humanística ou italiana.

${ }^{20}$ SERRÃO (Dicionário de história de Portugal e do Brasil, p. 296) afirma que as letras podem ser classificadas como encadeadas, formando uma "espécie de cadeia contínua, com raras separações de palavras e aspecto aparentemente de uniformidade indissolúvel".
} 
Acioli $^{21}$ assegura que os tipos de letras utilizados no Brasil nos séculos XVIII e XIX diferem muito pouco daqueles utilizados atualmente, como se pode observar em Ms1 e Ms2, que também registram diferenças paleográficas, dentre elas, quanto ao ss ( ) em < necessarias > (Ms1-16) ${ }^{22}$ ou ( $\left.2 / 4\right)$ ), em < sucessos > (Ms2-24), $z(z)$, em <rezultado> (Ms2-14), ou ( $z)$, em $<$ doze $>$ (Ms1-26), ocorrências que também corroboram a informação da autora.

\subsubsection{Características ortográficas}

A ortografia portuguesa, segundo Coutinho, ${ }^{23}$ tem sua história marcada por três períodos: fonético, pseudo-etimológico e simplificado. Gonçalves ${ }^{24}$ por sua vez, afirma existirem quatro tipos de sistema ortográfico: etimológico, misto, filosófico e simplificado.

O período fonético, que coincide com a fase arcaica do português, indo desde os primeiros documentos até o século XVI, é caracterizado pela busca de facilitação da leitura, aproximando a escrita, na medida do possível, à língua falada, sendo a "língua [era] escrita para o ouvido", segundo Coutinho. ${ }^{25}$ Nesse período, chamado de filosófico por Gonçalves, ${ }^{26}$ busca-se "restabelecer a biunivocidade entre a oralidade e a escrita".

O período pseudo-etimológico, que se inicia no século XVI indo até 1904, com a publicação da Ortografia Nacional, de Gonçalves Viana, foi influenciado pelo Renascimento, quando, ao serem redescobertos os escritores clássicos gregos e romanos, a escrita

\footnotetext{
${ }^{21}$ ACIOLI. A escrita no Brasil Colônia, p. 62.

${ }^{22}$ Leia-se Ms1-16 como Manuscrito 1, linba 16.

${ }^{23}$ COUTINHO. Pontos de gramática bistórica, p. 71-80.

${ }^{24}$ GONÇALVES. As idéias ortográficas em Portugal e pronunciar com acerto a língua portuguesa - de Madureira Feijó a Gonçalves Viana (1734-1911), p. 40. ${ }^{25}$ COUTINHO. Pontos de gramática bistórica, p. 71.

${ }^{26}$ GONÇALVES. As idéias ortográficas em Portugal e pronunciar com acerto a língua portuguesa - de Madureira Feijó a Gonçalves Viana (1734-1911), p. 40.
} 
submeteu-se à influência etimológica, capitaneada pelos pseudoetimologistas, os quais, retornando à origem do vocábulo em latim, restabeleceram letras há muito em desuso. Nesse período, de conformidade com Coutinho, ${ }^{27}$ conviveram "várias ortografias, dado que a etimologia [...] era uma ciência que dependia, em grande parte, da fantasia de cada escritor".

Operíodo etimológico, de acordo com Gonçalves, ${ }^{28}$ marcado principalmente pela publicação, em 1734, de Ortbographia ou arte de escrever e pronunciar com acerto a lingua portugueza, de João de Morais Madureira Feijó, é "plasmado na recuperação da representação gráfica dos étimos".

O sistema misto, segundo a mesma autora, constitui-se da convergência de vários princípios "como a etimologia e a pronúncia, podendo verificar-se versões mais ou menos fortes de etimologia, de grafias históricas, de adopção de grafias fonéticas, ou de sujeição ao uso".

Após a publicação da Ortografia Nacional, de Gonçalves Viana, em 1904, foram estabelecidos dois sistemas simplificados: o português e o luso-brasileiro, com a definição de vários princípios ortográficos, de maneira a se buscar uniformidade da escrita, por um lado, mas também, a simplificação da ortografia, por outro.

Segundo Santiago-Almeida ${ }^{29}$ apesar dos acordos na busca de unificação ortográfica do português,

a ausência de uma norma de fato para a escrita fez com que, principalmente no século XVIII, se apresentasse uma grafia variável, oscilante, emergindo ainda traços da modalidade oral, resquícios da fase da ortografia fonética, própria do período arcaico, em que os textos, segundo Maia (1986, p. 302), revelavam freqüentes situações de polivalência e de poligrafia.

${ }^{27}$ COUTINHO. Pontos de gramática histórica, p. 71.

${ }^{28}$ GONÇALVES. As idéias ortográficas em Portugal e pronunciar com acerto a Lingua Portuguesa - de Madureira Feijó a Gonçalves Viana (1734-1911), p. 40.

${ }^{29}$ SANTIAGO-ALMEIDA. Aspectos fonológicos do português falado na baixada cuiabana: traços de língua antiga preservados no Brasil (manuscritos da época das Bandeiras, século XVIII), p. 181. 
Quanto às características ortográficas, verifica-se em Ms1 e Ms2 o uso de:

a) consoantes dobradas de $g, c, f, l$ e $n$, como em <aggressores> (Ms1-3), <aggres-|sores> ${ }^{30}$ (Ms2-2/3), $<$ suc $=\mid$ cessos $>($ Ms1-21/22),$<$ differença $>($ Ms1-7 e Ms2-7), $<$ Illustrissimo > (Ms1-2 e 27), <Illustrissimo> (Ms2-1 e 30), $<$ Excellentissimo> (Ms1-2 e 27), <elle> (Ms1-10 e Ms2-10), $<$ cautellas $>$ (Ms1-16), <d'aquella $>$ (Ms1-22), < daquella $>$ (Ms 2-24), <annos> (Ms1-7 e Ms2-6).

b) $\boldsymbol{b}$, como em <n'hum> (Ms1-6 e Ms2-5), <huma> (Ms1-14 e Ms2-15), <a=| prehençaõ > (Ms1-13/14), <apre $\mid$ hençaõ > (Ms2-14/15), <vehemente> (Ms1-5 e Ms2-4).

c) ou, como em <dous> (Ms's1 e 2-6).

d) $z$, como em < caza > (Ms1-11 e Ms2-12), <pozitiva > (Ms1-14), <prizão> (Ms1- 16), <prizaõ > (Ms2-18), $<$ espantozo> (Ms1-22 e Ms2-25), < rezultado> (Ms1-13 e Ms214), <trez $>$ (Ms2-26).

e) oens, como em <combi=| naçoens > (Ms1-8/9), $<$ combinaçoens > (Ms2-9), < recomendaçoens > (Ms1-17 e Ms218), <averiguaçoens $>\left(\right.$ Ms1-18 e Ms2-20). ${ }^{31}$

\subsubsection{Dimensão e traçado das letras}

A dimensão das letras, maiúsculas e minúsculas, com hastes ascendentes e descendentes, mesmo com pequenos rebuscamentos, não prejudica a leitura dos manuscritos, uma vez que seus traços dificilmente avançam os limites da pauta posterior, como se pode ver nas reproduções abaixo:

\footnotetext{
${ }^{30}$ A barra ( | ), como em <aggres-| sores>, indica mudança de linha no manuscrito. ${ }^{31}$ Cf. ANDRADE. Estudo paleográfico e codicológico de manuscritos dos séculos XVIII e XIX: edições fac-similar e semidiplomática, p. 316-318.
} 


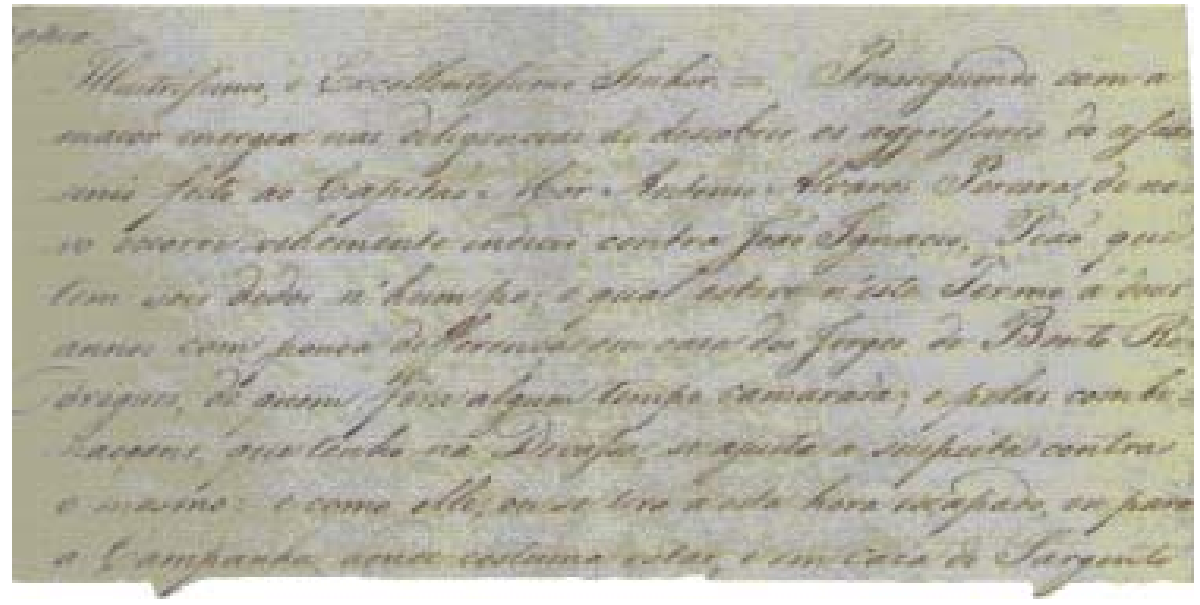

Figura 1 - Detalhe de Ms1 (linhas 1 a 11, recto)

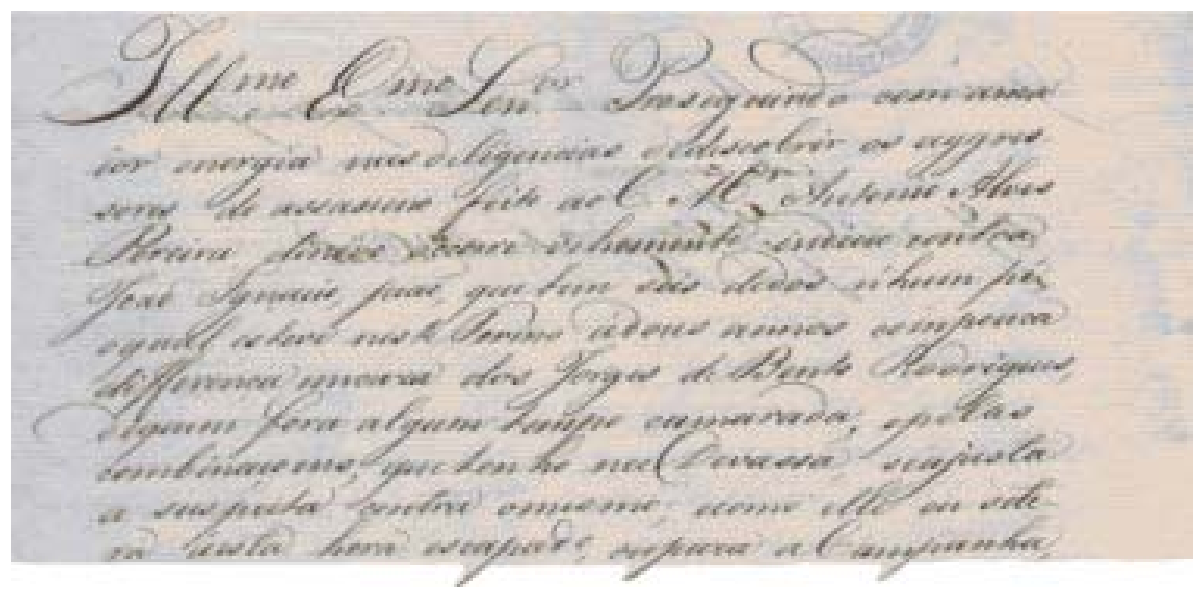

Figura 2 - Detalhe de Ms2 (linhas 1 a 11, recto)

Os detalhes de Ms1 e Ms2 mostram que há padronização da escrita, muito próxima da atual, com inclinação das letras à direita, respeito à pauta, apresentando regularidade das margens da mancha, à esquerda e à direita, tratando-se, portanto, de textos bem cuidados.

Além disso, o traçado das letras é marcado por pressão constante do instrumento de escrita sobre a matéria subjetiva, não 
havendo borrões nem excesso desigual de tinta, provavelmente em razão da melhor qualidade da tinta e do papel utilizados. ${ }^{32}$

A morfologia das letras, o seu traçado ou ductus (ordem de sucessão e sentido de seus traços), o ângulo (relação entre seus traços verticais e a pauta horizontal), o módulo (dimensão das letras em termos de pauta), e o peso (relação entre os traços finos e grossos) ${ }^{33}$ são regulares, evidenciando as mãos hábeis dos escribas, que demonstram habilidade e sedimentado conhecimento caligráfico.

Observando-se, por fim, os dois manuscritos, verifica-se que Ms1, cópia, possui o texto e a assinatura com as mesmas características caligráficas, sendo, portanto, apógrafo. ${ }^{34}$ Já Ms2, embora registre diferenças caligráficas entre o corpo do texto - linhas 1 a 34 - e a frase <Esta conforme > (Ms2-35) e a assinatura pelo <JuizdeForaJoseJoaquimCarneiro deMiranda Costa> (Ms2-36), trata-se também de testemunho lavrado por um copista, apógrafo, ${ }^{35}$ portanto, uma vez que, produzido por um amanuense, não foi conferido por seu autor intelectual, mas por quem solicitou a cópia.

\subsubsection{Abreviaturas (sistema braquigráfico)}

Acioli $^{36}$ afirma que houve, por vezes, ao longo da história, um uso excessivo de abreviaturas na produção de manuscritos, buscando a "economia do material de escrita, raro e caro à época e a lei do menor esforço, que levava o escriba a abreviar as palavras

\footnotetext{
${ }^{32}$ BECK (Manual de conservação de documento, p. 7-8) afirma que, entre 1809 e 1810, instalou-se a primeira fábrica de papel no Brasil, no Andaraí Pequeno, Rio de Janeiro, seguindo-se outras, em 1837 e 1852.

${ }^{33}$ CAMBRAIA. Introdução à crítica textual, p. 24.

${ }^{34}$ Idiógrafo é o manuscrito produzido por um escriba ou copista, mas revisto por seu autor intelectual.

${ }^{35}$ Apógrafo é o manuscrito produzido por terceiro, no caso, cópia.

${ }^{36}$ ACIOLI. A escrita no Brasil Colônia, p. 46.
} 
para dispensar menos tempo e energia no seu trabalho". Eram utilizadas por hábito ou convenção, para imprimir maior velocidade ao texto, dada a sua recorrência e previsibilidade, dentre outros motivos, permanecendo, aliás, seu uso, em determinados tipos de texto, até os dias atuais.

Spina $^{37}$ classifica as abreviaturas como sendo por:

a) sigla - representação da palavra pela letra inicial;

b) síncope - supressão de elementos gráficos no meio da palavra com letra(s) sobreposta(s);

c) numeral inicial com letra(s) sobreposta(s);

d) apócope - supressão de letra(s) ao final do vocábulo.

A seguir, serão apresentadas as abreviaturas encontradas em Ms1 e Ms2, com desdobramento indicado por Flexor, ${ }^{38}$ organizadas, pela ordem em cada linha, em edições fac-similar, diplomática e semidiplomática, ${ }^{39}$ recorrendo-se nesta aos caracteres itálicos para a explicitação do(s) elemento(s) suprimido(s).

a) Sigla ${ }^{40}$

\begin{tabular}{|ll|l|l|}
\hline & Ms2-12 & $<$ s. & $<$ Senbor $>$ \\
\hline 2 $C$ & Ms2-31 & $<$ v. & $<$ Vossa $>$ \\
\hline
\end{tabular}

\footnotetext{
${ }^{37}$ SPINA. Introdução à edótica, p. 44-49.

${ }^{38}$ FLEXOR. Abreviaturas: manuscritos dos séculos XVI ao XIX.

39 Para definições de edição semidiplomática, cf. item 3 adiante e nota 41 .

${ }^{40}$ ACIOLI (A escrita no Brasil Colônia, p. 46) classifica esse tipo de abreviatura como por suspensão ou apócope.
} 


\section{b) Síncope com letras sobrepostas}

\begin{tabular}{|c|c|c|c|}
\hline & Ms2-12 & $<\mathrm{All}^{\mathrm{z}}>$ & $<$ Alvarez $>$ \\
\hline & Ms2-3 & $<$ C.M. ${ }^{\mathrm{r}}>$ & <Capitaõ Mor> \\
\hline & Ms2-36 & $<$ Carn $^{\text {ro }}>$ & $<$ Carneiro $>$ \\
\hline & Ms2-33 & $<$ Confr. $^{\mathrm{e}}>$ & $<$ Conforme $>$ \\
\hline & Ms2-27 & $<$ D. ${ }^{\mathrm{s}}>$ & $<$ Deos $>$ \\
\hline & Ms2-18 & $<$ d. $^{\text {o }}>$ & $<$ dito $>$ \\
\hline 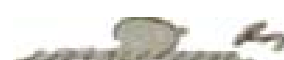 & Ms1-31 & $<$ empedim ${ }^{\text {tos }}>$ & $<$ empedimentos $>$ \\
\hline & Ms2-1 & $<$ Ex. $^{\text {mo }}>$ & $<$ Excellentissimo $>$ \\
\hline & Ms2-16 & $<$ Ex. $^{\mathrm{a}}>$ & $<$ Excellencia $>$ \\
\hline & Ms1-31 & $<$ Gov. $^{\circ}>$ & $<$ Governo $>$ \\
\hline & Ms2-1 & $<$ Illl. $^{\text {mo }}>$ & $<$ Illustrissimo $>$ \\
\hline & Ms2-36 & $<$ Joaq $^{\mathrm{m}}>$ & $<$ Joaquim $>$ \\
\hline Mela 2 & Ms $2-15 / 16$ & $<$ no $=\left|\operatorname{vam}^{e}\right\rangle$ & $<$ no $=\mid$ vamente $>$ \\
\hline
\end{tabular}




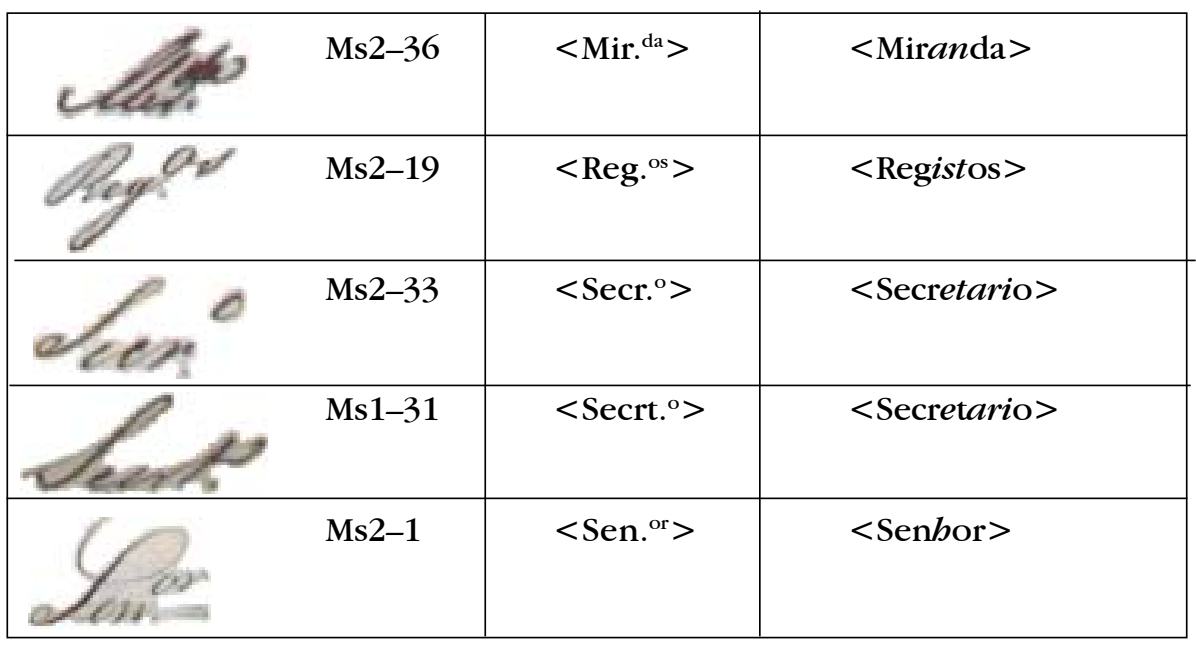

\section{Edições fac-similar e semidiplomática ${ }^{41}$}

Serão apresentadas a seguir as edições de Ms1 e Ms2: a fac-similar, reprodução mecânica, xerográfica e fotográfica do texto, que, de acordo com Spina, ${ }^{42}$ "reproduz com muita fidelidade as cacterísticas do original"; e a semidiplomática, ou diplomáticointerpretativa, que representa um grau baixo de intervenção do editor no manuscrito, com a transcrição tipográfica do texto e o desdobramento das abreviaturas.

\footnotetext{
${ }^{41}$ SPINA (Introdução à edótica, p. 77-85) define, além desses, os seguintes tipos de edição: diplomática, paleográfica e crítica. CAMBRAIA (Introdução à crítica textual, p. 91-103) apresenta classificação de tipos de edição, em que, concordando com Spina quanto às edições fac-similar, diplomática e crítica, chama de paleográfica a semidiplomática e a diplomático-interpretativa, acrescentando a interpretativa, resultado do grau máximo de intervenção do editor, e a modernizada, marcada pela modernização linguística do texto.

${ }^{42}$ SPINA. Introdução à edótica, p. 78-81.
} 
$\mathrm{Na}$ edição semidiplomática de Ms1 e Ms2, tendo-se por referência as orientações para a transcrição de manuscritos ${ }^{43}$ estabelecidas no II Seminário para a História do Português Brasileiro, realizado no período de 10 a 16 de maio de 1998, em Campos do Jordão (SP), serão adotados os seguintes critérios:

a) As linhas serão numeradas de cinco em cinco.

b) As abreviaturas serão desdobradas e os caracteres nelas suprimidos expressos em itálico.

c) Os diacríticos (til, apóstrofo, etc.), a acentuação, a pontuação e demais sinais serão mantidos como nos originais.

d) A ortografia será mantida como nos originais.

e) As fronteiras de palavras serão mantidas como nos originais.

f) O $s$ caudado ( ) será representado por $s$.

g) As assinaturas serão indicadas entre diples $(<>)$.

${ }^{43}$ MEGALE, H. et al. Normas para a transcrição de documentos manuscritos para a história do português do Brasil, p. p. 553-555. 


\section{Ms1 - Fólio 1r}

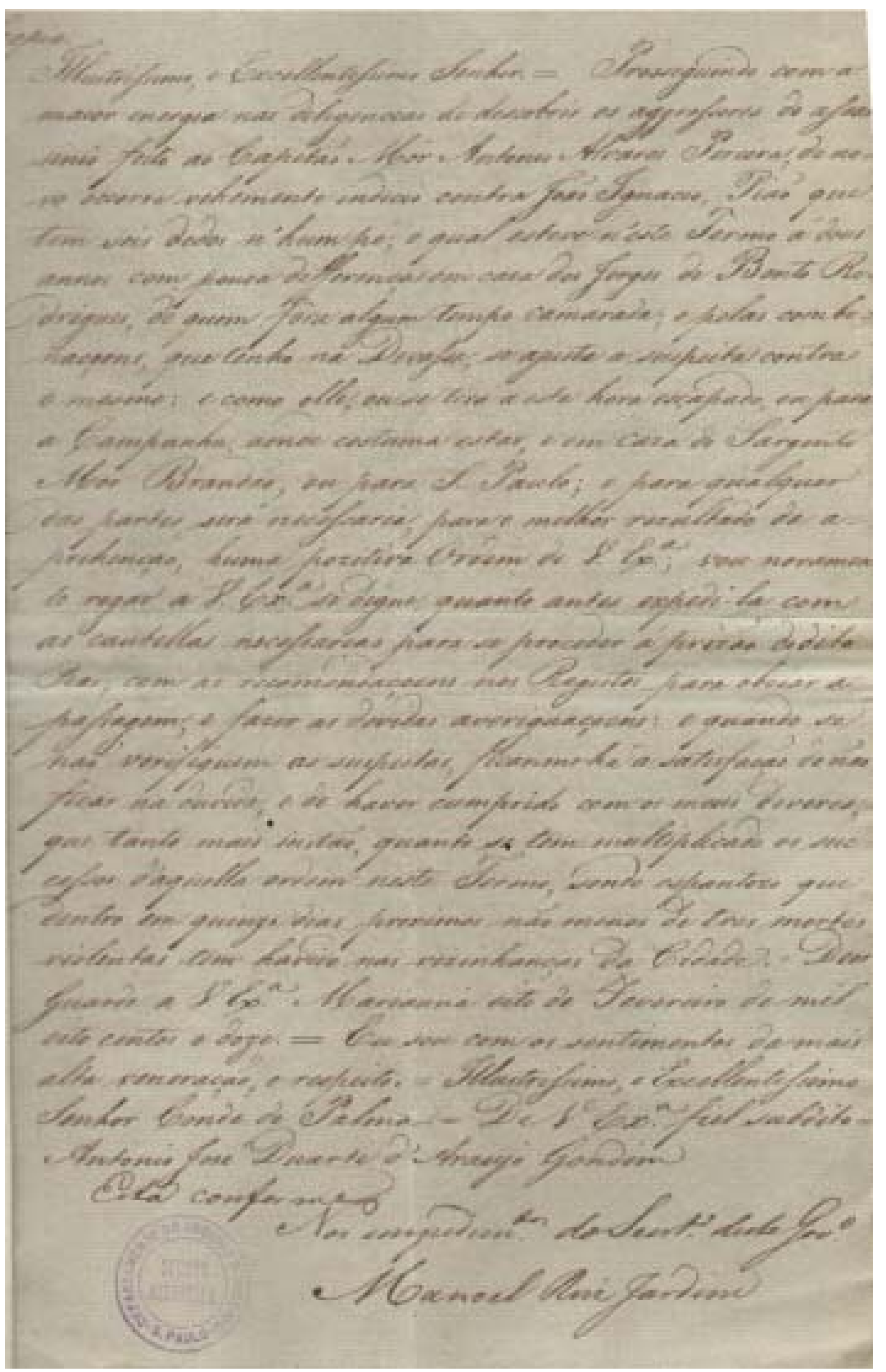




\section{Transcrição 1 - Fólio $1 r$}

\begin{tabular}{|l|l|}
\hline CÓDIGO DE IDENTIFICAÇÃO: APESP: 88-2-92 \\
\hline ASSUNTO & $\begin{array}{l}\text { Relato de diligências em andamento para a prisão de certo } \\
\text { peão, que tem seis dedos em um pé, assassino de autoridade } \\
\text { militar, que teria fugido para Campanha - MG ou São Paulo. }\end{array}$ \\
\hline LOCAL E DATA & Mariana - MG, 8 de fevereiro de 1812 \\
\hline ASSINATURA & Apógrafo \\
\hline
\end{tabular}

Copia.

Illustrissimo, e Excellentissimo Senhor. = Prosseguindo com a maior energia nas diligencias de descobrir os aggressores do assas sinio feito ao Capitaõ Mór Antonio Alvares Pereira, de no =

5 vo ocorre vehemente indicio contra Joaõ Ignacio, Piaõ que tem seis dedos n'hum pé; o qual esteve n'este Termo á dous annos com pouca differença em caza dos Jorges de Bento Ro = drigues, de quem fôra algum tempo camarada; e pelas combi = naçoens, que tenho na Devassa, se ajusta a suspeita contra o mesmo: e como elle, ou se terá a esta hora escapado, ou para a Campanha, aonde costuma estar, e em caza do Sargento Mór Brandaõ; ou para Saõ Paulo; e para qualquer das partes será necessaria, para o melhor rezultado da $\mathbf{a}=$ prehençaõ, huma pozitiva Ordem de Vossa Excellencia; vou novamen te rogar a Vossa Excellencia se digne quanto antes expedi-la com as cautellas necessarias para se proceder á prizão do dito Piaõ; com as recomendaçoens nos Registos para obviar a passagem, e fazer as devidas averiguaçoens: e quando se não verifiquem as suspeitas, ficar-me-há a satisfaçaõ de não ficar na duvida, e de haver cumprido com os meus deveres, que tanto mais instaõ, quanto se tem multiplicado os suc $=$ cessos d'aquella ordem neste Termo, sendo espantozo que dentro em quinze dias proximos naõ menos de tres mortes violentas tem havido nas vizinhanças da Cidade. $=$ Deos Guarde a Vossa Excellencia Marianna oito de Fevereiro de mil oito centos e doze. $=\mathrm{Eu}$ sou com os sentimentos da mais alta veneraçaõ, e respeito. = Illustrissimo, e Excellentissimo Senhor Conde de Palma. $=$ DeVossa Excellencia fiel subdito= <Antonio José Duarte d'Araujo Gondim.> Esta conforme Nos empedimentos doSecretario desteGoverno $<$ Manoel Rodriguez Jardim> 


\section{Ms2 - Fólio 1r}

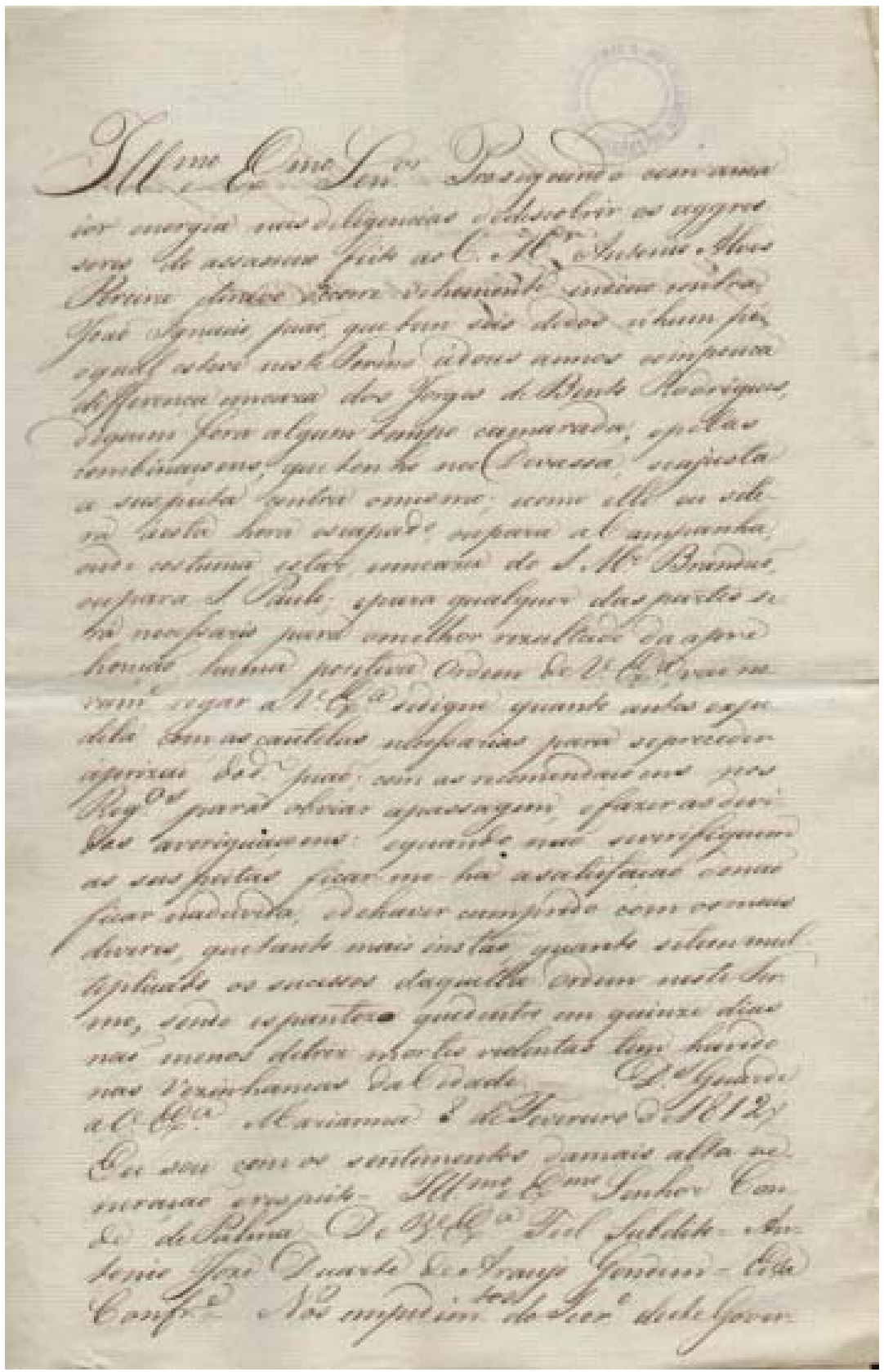


Transcrição 2 - Fólio 1r

\begin{tabular}{|l|l|}
\hline CÓDIGO DE IDENTIFICAÇÃO: APESP: 88-2-92 \\
\hline ASSUNTO & $\begin{array}{l}\text { Relato de diligências em curso para a prisão de um peão, } \\
\text { que tem seis dedos em um pé, assassino de autoridade } \\
\text { militar, que teria fugido para Campanha-MG, ou São Paulo. }\end{array}$ \\
\hline LOCAL E DATA & Não definidos \\
\hline ASSINATURA & Apógrafo \\
\hline
\end{tabular}

Copia.

Illustrissimo eExcellentissimo Senhor - Proseguindo com ama ior energia nas deligencias dediscobrir os aggres sores do assassino feito aoCapitaõ Mor Antonio Alves Pereira, dinovo occorre vehemente indicio contra

5 Joaõ Ignacio, piaõ, quetem seis dedos n'hum pé, o qual esteve nesteTermo ádous annos compouca differença emcaza dos Jorges deBento Rodrigues, dequem fora algum tempo camarada, epelas combinaçoens, quetenho naDevassa, seajusta a suspeita contra omesmo; ecomo elle ou sete rá áesta hora escapado, oupara aCampanha, onde costuma estar, eemcaza do Senhor Alvarez Brandaõ, oupara Sã̃ Paulo; epara qualquer das partes se rá necessario para omelhor rezultado da apre

15 hençaõ huma positiva Ordem deVossaExcellencia, vou no = vamente rogar aVossaExcellencia sedigne quanto antes expe dila com as cautelas necessarias para seproceder áprizaõ dodito piaõ; com as recomendaçoens nos Registos para obviar apassagem, efazer as devi das averiguaçoens: equando naõ severifiquem as suspeitas ficar-me-ha asatisfaçaõ denaõ ficar naduvida, edehaver cumprido com os meus deveres, quetanto mais instaô, quanto setem mul tiplicado os sucessos daquella ordem neste Ter mo, sendo espantozo quedentro em quinze dias naõ menos detrez mortes violentas tem havido nas vezinhanças daCidade. $=$ Deos Guarde aVossa Excellencia Marianna 8 deFevereiro de $1812 \bullet$ Eu sou com os sentimentos damais alta ve neraçaõ erespeito $=$ Illustrissimo eExcellentissimo Senhor Con de dePalma $=$ DeVossa Excellencia Fiel Súbdito $=<$ An tonio Jozé Duarte deAraujo Gondim> = Esta Conforme $=$ Nos empedimentos doSecretario desteGover - 
Ms2 - Fólio 1v

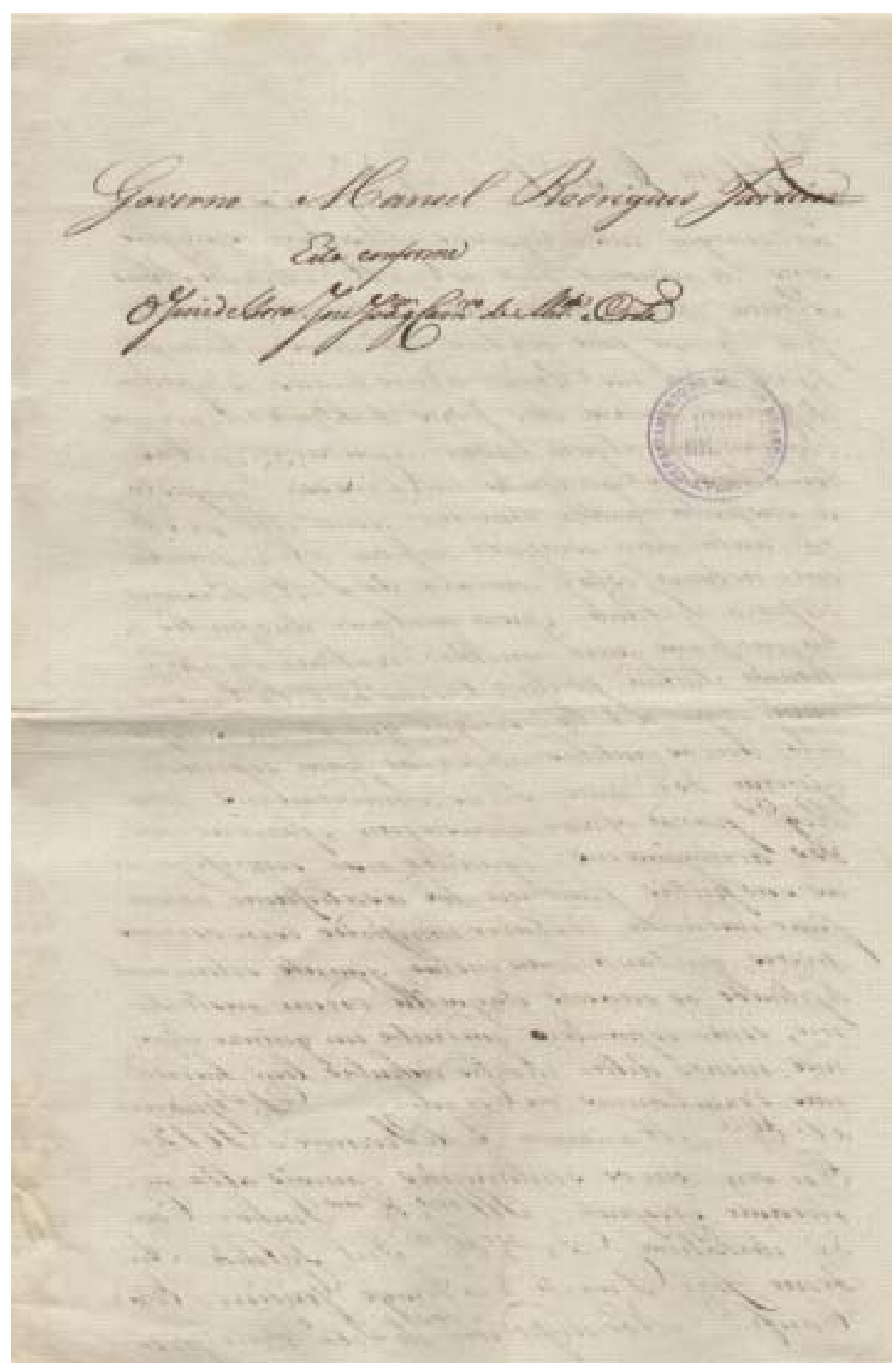




\section{Transcrição 2 - Fólio 1v}

Governo $=<$ Manoel Rodrigues Jardim $>=$ Esta conforme

OJuizdeFora $<$ JoseJoaquimCarneiro deMiranda Costa $>$

\section{Cotejo de Ms1 e Ms2}

As intervenções do escriba na transmissão de manuscritos ocorrem, em geral, em razão de seu grau de instrução, cansaço, longa jornada de trabalho ininterrupto, cultura, condições de conservação dos originais, censura própria ou de superior, do estado ou da igreja, pressa, tempo exíguo para se executar uma tarefa, disponibilidade e qualidade do papel, da tinta, do instrumento de escrita e do princípio de economia de papel.

Em Ms2, que é cópia de Ms1, sendo Ms1 identificado como <Copia> (Ms1-1), essas intervenções, ao que tudo indica, foram deliberadamente feitas pelo copista, dado o expressivo número de abreviaturas e o não estabelecimento de fronteiras entre considerável quantidade de palavras.

Parece haver evidências sinalizando que Ms1 tenha sido utilizado para se fazer a cópia (Ms2), uma vez que a expressão $<$ Esta $\mid$ Conforme $>$ (Ms2-32/33) pertence também à primeira cópia - <Esta conforme $>$ (Ms1-30).

Reforça essa tese o fato de que $<$ Esta conforme $>$ (Ms2-35) guarda diferenças caligráficas evidentes com $<$ Esta $\mid$ Conforme $>$ (Ms2-32/33), que, por sua vez, revela semelhanças caligráficas com o corpo de Ms2, à exceção de <Esta conforme|OjuizdeForaJose JoaquimCarneiro deMiranda Costa $>$ (Ms2-35/36), muito semelhantes caligraficamente entre si, por se tratar de um segundo punho, diferindo, não obstante, do restante do texto (Ms2-1/34).

Fazendo-se o cotejo entre Ms1 e Ms2, podem ser observadas as seguintes características: 
a) Variação do número de linhas

O Ms2 possui 36 linhas (33 no fólio 1r e 3 no fólio 1v), sendo mais extenso em razão, dentre outros fatores, de ter duas linhas a mais do que o Ms1: <Esta conforme> (Ms2-35) e $<$ OJuizdeForaJoseJoaquimCarneiro deMiranda Costa > (Ms236), e de considerável número de abreviaturas - vinte e duas. Já o Ms1, menos extenso, tem 32 linhas, todas no fólio 1r, mesmo registrando < próximos> (Ms1-23), palavra suprimida no Ms2, além de possuir apenas oito abreviaturas.

b) Datação

O Ms1 está datado de 08.02.1812, enquanto o Ms2, cópia de Ms1, não possui data nem local onde foi escrito.

c) Fronteiras de palavras

O Ms1 possui apenas três ocorrências do não estabelecimento de fronteiras de palavras: <DeVossa Excellencia $>$ (Ms1-28), $<$ doSecretario $>$ (Ms1-31) e < desteGoverno $>$ (Ms1-31).

Já o Ms2 apresenta sessenta e sete ocorrências, dentre elas, apenas para ilustrar: <oCapitaõ Mor > (Ms2-3), <dinovo> (Ms2-4), <ádous> (Ms2-6), <emcaza> (Ms2-7), <dequem> (Ms2-8), <ecomo> (Ms2-10), <oupara> (Ms2-13), <efazer> (Ms2-19), <edehaver $>\quad($ Ms2-22), <daCidade $>$ (Ms2-27) e $<$ DeVossaExcellencia $>$ (Ms2-31).

Esses exemplos são evidências de que o escriba, amanuense ou copista, de Ms2 optou por alterar Ms1, nesse aspecto, aumentando significativamente o número do não estabelecimento de fronteiras entre palavras, de três, em Ms1, para sessenta e sete, em Ms2.

d) Abreviaturas

O Ms1 contém nove abreviaturas, enquanto o Ms2 vinte e quatro. A título de exemplo, vejam-se: 


\begin{tabular}{|c|c|}
\hline Ms1 & Ms2 \\
\hline$<$ Illustrissimo, e Excellentissimo $>(\text { Ms1-2) })^{44}$ & $<$ Illl $^{\text {mo }} \mathrm{eEx}^{\mathrm{mo}}>(\mathrm{Ms} 2-1)$ \\
\hline <Capitaõ Mor > (Ms1-4) & $<$ C.M. $^{\mathrm{r}}>(\mathrm{Ms} 2-3)$ \\
\hline$<$ Registos $>$ (Ms1-17) & $<$ Reg. ${ }^{\text {os }}>$ (Ms2-19) \\
\hline < Illustrissimo, e Excellentissimo > (Ms1-27) & $<$ Ill. $^{\text {mo }}$ eEx. ${ }^{\text {mo }}>(\mathrm{Ms} 2-30)$ \\
\hline
\end{tabular}

e) Uso de maiúsculas.

Observem-se, como exemplos:

\begin{tabular}{|c|c|}
\hline Ms1 & Ms2 \\
\hline < Piã̃ > (Ms1-5) & < piaõ > (Ms2-5) \\
\hline$<$ Piaõ > (Ms1-17) & $<$ piaõ $>$ (Ms2-18) \\
\hline
\end{tabular}

f) Pontuação.

Observem-se, como exemplos:

\begin{tabular}{|c|c|}
\hline Ms1 & Ms2 \\
\hline <Piaõ que > (Ms1-5) & <piaõ, que> (Ms2-5) \\
\hline <pé; o qual> (Ms1-6) & < pé, |o qual> (Ms2-5/6) \\
\hline$<$ camarada; e pelas $>($ Ms1-8) & <camarada, epelas > (Ms2-8) \\
\hline <mesmo: e como> (Ms1-10) & $<$ mesmo; ecomo $>$ (Ms2-10) \\
\hline <veneraçaõ, e respeito> (Ms1-27) & <ve-|neraçaõ erespeito> (Ms2-29/30) \\
\hline$<$ Illustrissimo, e Excellentissimo $>$ (Ms1-27) & $<$ Illustrissimo eExcelentissimo $>(\mathrm{Ms} 2-30)$ \\
\hline
\end{tabular}

g) Acentuação.

Observem-se, como exemplos:

\begin{tabular}{|l|l|}
\hline \multicolumn{1}{|c|}{ Ms1 } & \multicolumn{1}{c|}{ Ms2 } \\
\hline <a esta> (Ms1-10) & <áesta> (Ms2-11) \\
\hline <ficar-me-há> (Ms1-19) & <ficar-me-ha> (Ms2-21) \\
\hline <não> (Ms1-19) & <naõ > (Ms2-21) \\
\hline
\end{tabular}

${ }^{44} \mathrm{~A}$ indicação (2) refere-se ao número da linha na transcrição. 
h) Supressões e acréscimos.

São as seguintes as ocorrências:

\begin{tabular}{|l|l|}
\hline \multicolumn{1}{|c|}{ Ms1 } & \multicolumn{1}{|c|}{ Ms2 } \\
\hline$<$ proximos $>$ (Ms1-23) & $<\emptyset>($ Ms2-25/26) \\
\hline$<\varnothing>$ (ao final de Ms1) & $<$ Esta conforme $>$ (Ms2-35) \\
\cline { 2 - 3 } & $\begin{array}{l}<\text { OJuizdeForaJoseJoaquimCarneirode } \\
\text { Miranda Costa }>\text { (Ms2-36) }\end{array}$ \\
\hline
\end{tabular}

\section{i) Outras características}

Há outras características, de natureza diversa, conforme se pode observar, a título de exemplo no quadro a seguir, como poligrafia (1 a 5), traços de oralidade na escrita (6 e 7), emprego de advérbios (8), colocação de pronome antes ou depois do advérbio de negação (9), duplicação de consoantes (10 e 11) e uso de apóstrofo (12), que distinguem os dois manuscritos. Observemse:

\begin{tabular}{|c|c|c|}
\hline & Ms1 & Ms2 \\
\hline 1. & $<$ assas $\mid$ sinio $>($ Ms1-2/3) & $<$ assassino $>$ (Ms2-3) \\
\hline 2. & $<$ pozitiva $>$ (Ms1-14) & $<$ positiva $>$ (Ms2-15) \\
\hline 3. & $<$ suc $=\mid \operatorname{cessos}>(\mathrm{Ms} 1-21 / 22)$ & $<$ sucessos $>$ (Ms2-24) \\
\hline 4. & $<$ de tres $>($ Ms1-23) & $<$ detrez > (Ms2-26) \\
\hline 5. & <José> (Ms1-29) & <Jozé> (Ms2-32) \\
\hline 6. & $<$ descobrir > (Ms1-3) & <discobrir > (Ms2-2) \\
\hline 7. & $<$ de no $=\mid$ vo $>(\operatorname{Ms} 1-4 / 5)$ & $<$ dinovo $>$ (Ms2-4) \\
\hline 8. & < aonde > (Ms1-11) & <onde> (Ms2-12) \\
\hline 9. & <se| não verifiquem> (Ms1-18/19) & $<$ naõ severifiquem $>$ (Ms2-20) \\
\hline 10. & < cautellas > (Ms1-16) & $<$ cautelas $>$ (Ms2-17) \\
\hline 11. & <d'aquella> (Ms1-22) & $<$ daquella $>$ (Ms2-24) \\
\hline 12. & $<$ d'Araujo $>$ (Ms1-29) & $<$ deAraujo $>$ (Ms2-32) \\
\hline
\end{tabular}




\section{Conclusão}

O papel do filólogo e do crítico textual deve ser o de procurar restituir o documento, manuscrito ou impresso, à sua forma genuína, de maneira a preservar, no seu trabalho de edição, a vontade última do autor, efetuando, para isso, análises, dentre elas a paleográfica, como no presente caso, preparando o texto para publicação.

As atividades do labor filológico devem ser desenvolvidas com o devido cuidado a fim de que o resultado obtido seja de valia para o crítico literário, o linguista, o historiador e demais profissionais de áreas afins que, assim, poderão dispor de material de estudo confiável para empreenderem suas pesquisas com maior segurança.

Foram feitas aqui as edições fac-similar e semidiplomática de Ms1 e de Ms2, ambos cópias, como visto, realizando-se o cotejo entre os dois documentos, com o objetivo de se proceder à análise de suas características paleográficas e das diferenças que há entre eles, fruto de intervenções do escriba, copista ou amanuense, intencionais ou não, que os caracterizam como testemunhos oriundos de original não abordado aqui.

Enfim, as análises que se procuraram fazer neste artigo, em especial as relativas às diferenças entre os dois manuscritos, são evidências de que o estudo da tradição dos documentos, concretizada por sua transmissão até os dias atuais, exige do filólogo dedicação e empenho redobrados com vistas a levar a bom termo a árdua tarefa de fixação do texto.

Resumen: Este trabajo se propone estudiar dos manuscritos del siglo XIX. El primero (Ms1), escrito en Mariana, Minas Gerais, el 8 febrero de 1812; el segundo (Ms2), sin fecha y local. Los dos documentos pertenecen al Archivo Público de São Paulo.Ambos son copias, el Ms2 es copia de Ms1. Para este estudio se hicieron las ediciones fac-similar y semidiplomática, con el objetivo de hacer la comparación de los dos manuscritos para analizar las similitudes y diferencias que hay entre 
ambos, bien como hacer los comentarios paleográficos, con el objetivo de preparlos para el trabajo lingüístico.

Palabras-1lave: Crítica textual; filología; manuscrito; edición; paleografía.

\section{Referências}

ACIOLI, Vera Lúcia Costa. A escrita no Brasil Colônia: um guia para leitura de documentos manuscritos. 2. ed. Recife: Fundação Joaquim Nabuco; Massangana, 2003.

ANDRADE, Elias Alves de. Estudo paleográfico e codicológico de manuscritos dos séculos XVIII e XIX: edições fac-similar e semidiplomática. Tese (Doutorado), Faculdade de Filosofia, Letras e Ciências Humanas, Universidade de São Paulo, 2007.

Aspectos paleográficos em manuscritos dos séculos XVIII e XIX. Filologia e Linguística Portuguesa, São Paulo, n. 10/11, p. 149-172, 2008/2009.

AZEVEDO FILHO, Leodegário A. de. Iniciação à crítica textual. Rio de Janeiro: Presença Edições/EdUSP, 1987.

BECK, Ingrid. Manual de consevação de documentos. Rio de Janeiro: Arquivo Nacional - Ministério da Justiça, 1985.

BLANCO, Ricardo Román. Estudos paleográficos. São Paulo: Laserprint, 1987.

CAMBRAIA, César Nardelli. Introdução à crítica textual. São Paulo: Martins Fontes, 2005.

COUTINHO, Ismael de Lima. Pontos de gramática bistórica. 7. ed. Rio de Janeiro: Ao Livro Técnico S/A, 1976.

DIAS, Madalena Marques; BIVAR, Vanessa dos Santos Bodstein. Paleografia para o período colonial. In: SAMARA, E. de M. (Org.) Paleografia e fontes do período colonial brasileiro. São Paulo: Humanitas/FFLCH-USP, 2005. (Estudos CEDHAL, nova Série, 11). p.11-38.

FLEXOR, Maria Helena Ochi. Abreviaturas: manuscritos dos séculos XVI ao XIX. 2. ed. São Paulo: Editora UNESP/Edições do Arquivo Público do Estado de São Paulo, 1991. 
GONÇALVES, Maria Filomena. As idéias ortográficas em Portugal e pronunciar com acerto a língua portuguesa - de Madureira Feijó a Gonçalves Viana (1734-1911). Lisboa: Fundação Calouste GulbenkianFundação para a Ciência e Tecnologia-MCES, 2003.

HIGOUNET, Charles. História concisa da escrita. Tradução da 13. ed. corrigida por Marcos Marcionilo. São Paulo: Parábola Editorial, 2003.

LEÃO, Duarte Nunes de. Ortografia e origem da língua portuguesa. Introdução, notas e leituras de Maria Leonor Carvalhão Buescu. Lisboa: Imprensa Nacional-Casa da Moeda, 1983.

MAIA, Clarinda de Azevedo. História do galego-português. Lisboa: Fundação Calouste Gulbenkian - Junta Nacional de Investigação Científica e Tecnológica, 1986.

MEGALE, Heitor. Pesquisa filológica: os trabalhos da tradição e os novos trabalhos em língua portuguesa. Estudos Lingüísticos, São José do Rio Preto, v. XXVII, p. 3-28, 1998.

MEGALE, Heitor et al. Normas para a transcrição de documentos manuscritos para a história do português do Brasil. In: MATTOS E SILVA, Rosa Virgínia. (Org.). Para a história do português brasileiro: primeiros estudos. São Paulo: Humanitas / Fapesp, 2001. v. II, p. 553-555.

SANTIAGO-ALMEIDA, Manoel Mourivaldo. Aspectos fonológicos do português falado na baixada cuiabana: traços de língua antiga preservados no Brasil (manuscritos da época das Bandeiras, século XVIII). Tese (Doutorado), Faculdade de Filosofia, Letras e Ciências Humanas, Universidade de São Paulo, 2000.

SERRÃO, Joel. Dicionário de história de Portugal e do Brasil. Lisboa: Iniciativas Editoriais, 1971.

SPAGGIARI, Barbara \& PERUGI, Maurizio. Fundamentos da crítica textual. Rio de Janeiro: Lucerna, 2004.

SPINA, Segismundo. Introdução à edótica: crítica textual. São Paulo: Cultrix, 1977. 